\title{
The Simultaneous Monitoring System for Gaseous Pollutants and Oxygen in Flue Gases by a Voltammetric Detector
}

\author{
Ken NOZAKI*, Hiroko KANEKO ${ }^{\dagger}$, Osamu HAMAMOTO ${ }^{\dagger \dagger}$, \\ Shunich UCHIYAMA ${ }^{\dagger+}$ and Toshiyuki HOBO ${ }^{\dagger+\dagger}$
}

Received January 16, 1998 ; Accepted March 18, 1998

\section{INTRODUCTION}

Sulfur dioxide and nitrogen oxides, as well as the dust, are main air pollutants exhausted from stationary combustion facilities especially in case of heavy oil and coal burning boilers.

These facilities, relatively larger scale in Japan, are bound to equip the monitoring system for the pollutants. The oxygen concentration also should be measured simultaneously, since the allowable emission level for nitrogen oxides depends on the oxygen concentration in combustion gases. Generally, three kinds of monitoring systems for sulfur dioxide, nitrogen oxides and oxygen should be equipped in flues of combustion gases, and three different methods would be adopted for the maintenance of these analysers including sampling units. To simplify the combustion flue gas monitoring, a simultaneous system for these chemical components was assembled with a new voltammetric detectors using the aminopolycarbonato iron complex solution as an absorbent; and demonstrated by using the combustion gas of heavy oil boiler.

\section{EXPERIMENTAL}

Figure 1 and Fig.2 show the structure of the voltammtric detector and the block diagram of the monitoring system for sulfur dioxide, nitrogen oxides and oxygen concentrations. The sample gas was introduced into the electrolytic solution directly. The pollutants and oxygen in combustion gases were partially absorbed into the electrolyte of

Electrotechnical Laboratory (1-1-4 Umezono, Tsukuba 305-8568, Japan)

† Tsukuba Materials Information Laboratory ( 3 23-4 Ninomiya, Tsukuba 305-0051, Japan),

${ }^{\dagger}$ Mitsui Engineering \& Shipbuilding Co., Ltd. (Tsukiji, Chuo-ku, Tokyo 104-8439, Japan)

${ }^{\dagger+}$ Saitama Institute of Technology (1690 Fusaiji, Okabe, Saitama 369-02, Japan)

${ }^{\dagger+}{ }^{\dagger}$ Tokyo Metropolitan University (1-1 Minami-

Osawa, Hachioji City, Tokyo 192-0364, Japan)

Key Words : Voltammetry, Aminopolycarbonato iron, Gas analyser, Boiler effluent gas

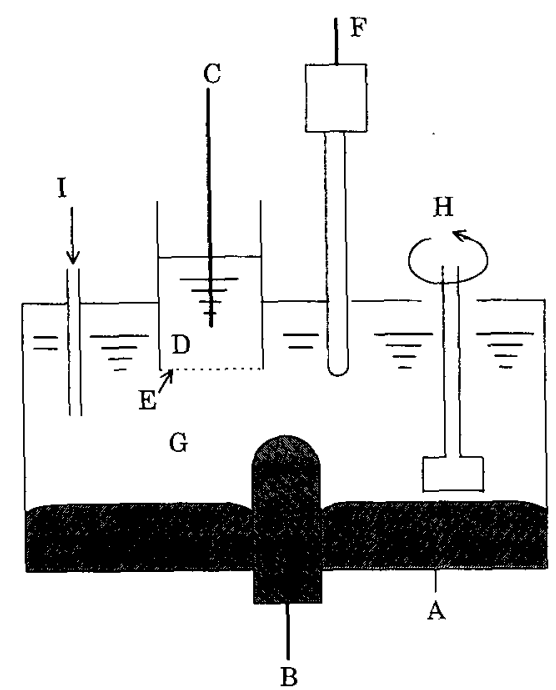

Fig.1 The structure of the voltammetric detector.

A : Hg pool electrode ( $60 \mathrm{~mm}$ diameter),

B : Hg stationary electrode ;(3mm diameter),

C : counter electrode (Pt wire),

$\mathrm{D}$ : solution of caunter electrode chamber $(0.5 \mathrm{M} \mathrm{NaHP})$,

$\mathrm{E}$ : cation exchange membrane (Asahi Glass (MV),

$\mathrm{F}$ : reference electrode (saturated calomel electrode),

$\mathrm{G}$ : electrolytic solution $(0.2 \mathrm{MFe}$ EDTA containing $0.5 \mathrm{M}$ $\mathrm{NaHPO}_{4}, 50 \mathrm{ml}$ ),

$\mathrm{H}$ : rotating rod $(600 \mathrm{rpm})$

I : sample gas (flow rate : $75 \mathrm{ml} \mathrm{min.} \cdot{ }^{-1}$ )

$0.2 \mathrm{M}$ ethylenediaminetetraacetato iron(II), $\mathrm{Fe}$ (II) EDTA, solution containing $0.5 \mathrm{M} \mathrm{NaHPO}_{4}$, and form sulfurous acid, $\mathrm{H}_{2} \mathrm{SO}_{3}$, nitrosyl complex, $\mathrm{Fe}$ (II) NOedta, and iron (III) complex respectively.1)

$$
\begin{aligned}
\mathrm{NO}+\mathrm{Fe}(\mathrm{II}) \mathrm{EDTA} \rightleftharpoons \mathrm{Fe}(\mathrm{II}) \mathrm{NO} \text { EDTA } \\
\mathrm{NO}_{2}+3 \mathrm{Fe}(\mathrm{II}) \mathrm{EDTA}+2 \mathrm{H}+\rightarrow \mathrm{Fe}(\text { II }) \mathrm{NO} \text { EDTA } \\
+2 \mathrm{Fe}(\text { II }) \text { EDTA }+\mathrm{H}_{2} \mathrm{O} \\
\mathrm{SO}_{2}+\mathrm{H}_{2} \mathrm{O} \rightleftharpoons \mathrm{H}_{2} \mathrm{SO}_{3}
\end{aligned}
$$

In the voltammetric cell, the species formed on absorbing were reduced electrochemically at the stationary electrode in the cell, and determined by voltammetric methods, such as DC, AC or 


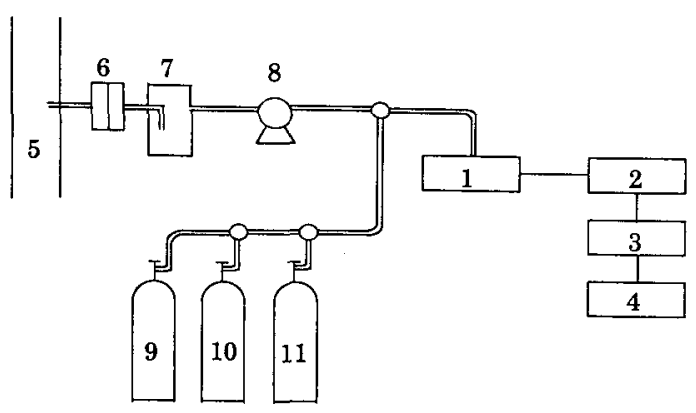

Fig.2 The block diagram of the combustion flue gas monitoring system.
1: detector,
2: polarograph,
3: data processor,
4: printer,
5: flue,
6: filter,
7: trap,
8: air pump,
9: standard gas, $\mathrm{NO}$,
10: standard gas, $\mathrm{SO}_{2}$,
11: standard gas, $\mathrm{O}_{2}$.

differential pulse polarography. ${ }^{2)}$ The concentration of iron (II) complex which absorbed nitrogen oxides was decreased by oxygen oxidation, and iron (III) complex was accumlated. Therefore, the iron (III) complex was mainly reduced on the $\mathrm{Hg}$ pool electrode at $-0.15 \mathrm{~V}$ vs. $\operatorname{SCE}(\mathrm{pH} 4)$, and oxygen concentration was monitored by measuring the current of the $\mathrm{Hg}$ pool electrode because the formation rate of iron (III) complex corresponded to the oxgen concentration (eq.4). The reason why influence of $\mathrm{NO}_{2}$ on oxygen monitoring could be neglected will be mentioned later. The $\mathrm{Hg}$ pool electrode and the solution were stirred by a rotating rod at $600 \mathrm{rpm}^{3}$ )

Sulfur dioxide and nitrogen oxides were determined by potential sweeping methods on the $\mathrm{Hg}$ stationary electrode at $-0.6 \mathrm{~V}$ and $-0.75 \mathrm{~V}$ vs. $\mathrm{SCE}(\mathrm{pH} 4)$, respectively.

A combustion gas from a heavy oil boiler was employed as a sample, and the concentrations of sulfur dioxide, nitrogen oxides and oxygen in the gas were measured by a NDIR-sulfur dioxide monitor, a chemiluminescent nitrogen oxides analyser and a galvanometric oxygen monitor, respectively. The total system of this demonstration is shown in Fig.3.

\section{RESULTS AND DISCUSSION}

The $\mathrm{DC}$ and $\mathrm{AC}$ polarograms for the electrolytic solution contacted with a combustion gas are shown in Fig.4(a) and (b), respectively. In the DC polarogram, anodic oxidation and cathodic

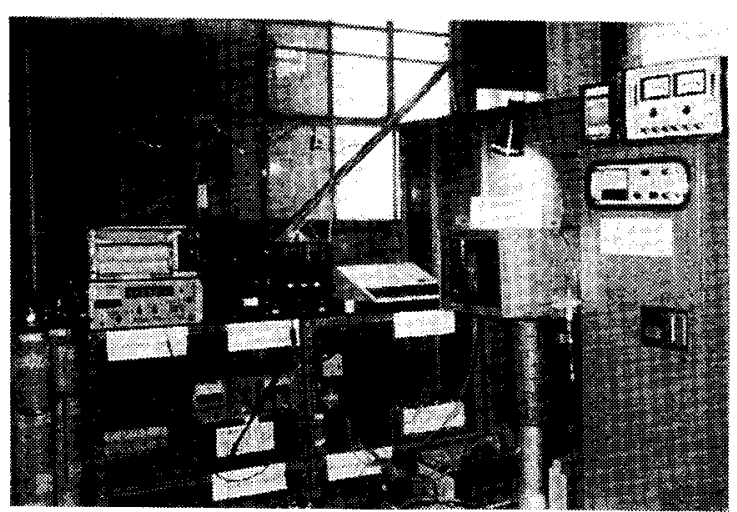

Fig.3 The picture of the experimental system for the flue gas monitoring.

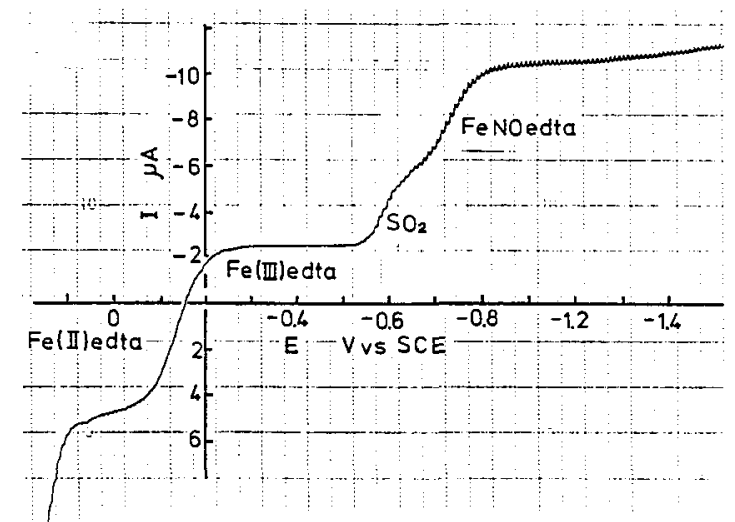

Fig.4(a) DC Polarogram of the absorbebnt. Scanning rate : $100 \mathrm{mV}$ min. $^{-1}$

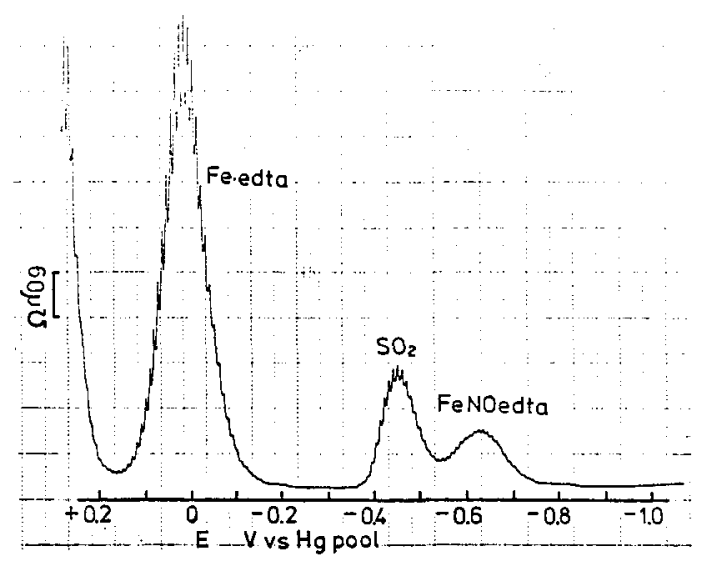

Fig.4(b) AC Polarogram of the absorbebnt. Scanning rate $: 100 \mathrm{mV}$ min. ${ }^{-1}$

reduction for iron II and III complexes were observed as a reversible wave of one electron transfer reaction in weak acid solution. ${ }^{3)}$ The mechanisms of reducing reactions for sulfurous acid and nitrosyl complex are variable in the reversibility and the number of electron depending 

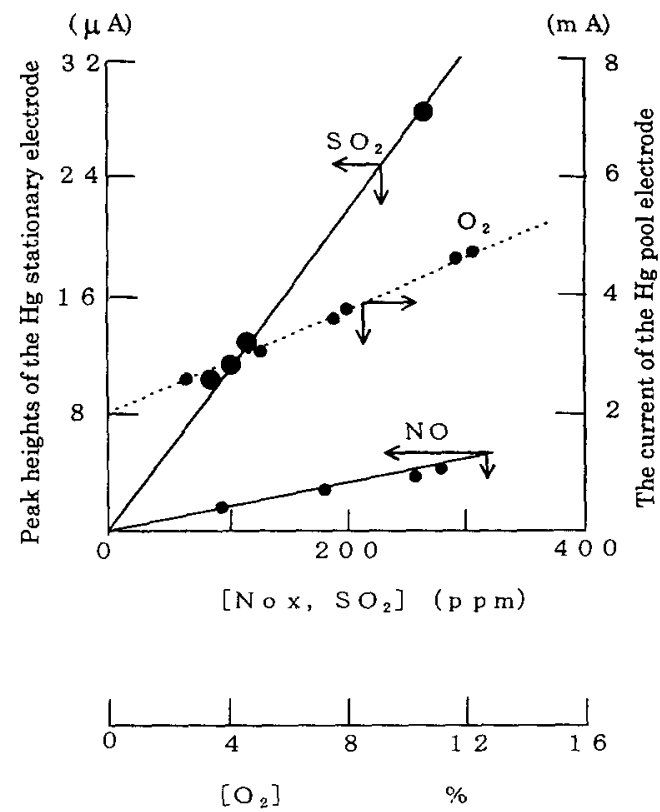

Concentrations measured by gas analysers

Fig.5 The comparison of the simultaneous monitoring system with commercial gas analysers in the monitoring of a boiler effluent gas.

$$
\begin{aligned}
& \text { Hg stationary electrode : }-0.30 \sim-0.70 \mathrm{Vvs} \text {. } \\
& \mathrm{SCE}, 180 \mathrm{mV} \text { min. }{ }^{-1} \\
& \mathrm{Hg} \text { pool electrode : }-0.15 \mathrm{~V} \text { vs. SCE }
\end{aligned}
$$

on $\mathrm{pH}$ of the solution. ${ }^{4}$ ) The $\mathrm{pH}$ value of $\mathrm{Fe}$ (II) EDTA solution is slightly raised by oxygen oxidation because of increasing hydroxyl ion concentration, though the buffering characteristics of EDTA. It was sufficient to keep the $\mathrm{pH}$ value constant by employing $0.5 \mathrm{M} \mathrm{NaHPO}_{4}$. Since the reduction waves performed high quantitative characteristics under constant $\mathrm{pH}$ conditions, ${ }_{1}^{3)}$ the monitoring could be conducted by measuring the wave heights for sulfur dioxide and nitrogen oxides using an $\mathrm{AC}$ method which is able to separate the waves easily as shown in Fig.4 (b). The differential pulse method seemed to obtain more high scanning rate than the $\mathrm{AC}$ method.

The comparison of the monitoring system built as a trial with commercial gas analysers for sulfur dioxide, nitrogen oxides and oxygen is shown in Fig.5. It took a little time for the detector to gain new gas-solute equilibrium when the concentrations of pollutants and oxygen were varied in the combustion gas. The delay of responce to regain new equilibrium was within three minutes in this system, compared with one or two minutes for the commercial three monitors of sulfure dioxide, nitrogen oxides and oxygen. It seems to be relatively easy to improve the response time by means of optimum design of the detector.

In the weak acid $\mathrm{Fe}$ (II ) EDTA solution, approximate $70 \%$ of nitrogen dioxide is converted to the nitrosyl complex ${ }^{4)}$. Therefore, it is necessary to compensate these conversion rates for high accurate measurements. However, since the proportion of nitrogen dioxide in the oxides is less than $10 \%$ and usually several percents in ordinary boiler effluent gases. The coexistence of nitrogen dioxide exerts no practical problem on the analytical precision of Nox and oxygen measurements as shown in the performance of Fig.5.

This electroanalytical system has been developed for flue gas monitoring of heavy oil burning boiler, however, it is now much expected to utilize in coal or tar combustion boilers which are main emission sources of components for acid rains.

\section{References}

1) H. Hasui, H. Miki, M. Hashimoto, N. Nakahar and O. Hamamoto, J. Chem. Soc. Japan, 1978(4), 626 (1978).

2) H. Kaneko, K. Nozaki and T. Ozawa, Abstracts of the 25th Meeting of Coordination Chemistry, 127 (1975).H. Kaneko and K. Nozaki, Review of Polarography, 23, 104 (1977).

3) O. Hamamoto, K.Nozaki, H. Kaneko and T. Ozawa, Review of Polarography, 25, 66 (1979).

4) O. Hamamoto, S. Uchiyama, K. Nozaki and G. Muto, Bunseki Kagaku, 28 (2), 118 (1979).

S. Uchiyama, K. Nozaki and G. Muto, Bunseki Kagaku, 26, 224 (1977).

S. Uchiyame and G. Muto, J. Electroanal. Chem., 127, 275 (1981). 